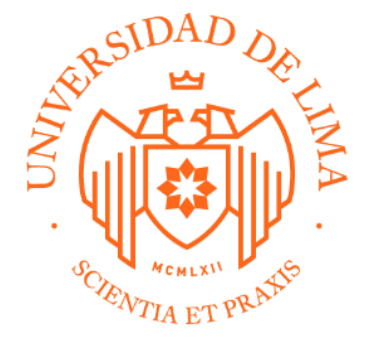

Universidad de Lima

Facultad de Comunicación

Carrera de Comunicación

\title{
DISIDENCIA Y CONCORDANCIA LOS CAMINOS BIFURCADOS DE LA REALIZACIÓN AUDIOVISUAL
}

Trabajo de Suficiencia Profesional para optar el Título Profesional de Licenciado en Comunicación

\section{RICARDO ARTURO AYALA ROJAS}

Código 872051

\section{Asesor: JAIME BAILÓN}

Lima - Perú

11 de Noviembre de 2019 


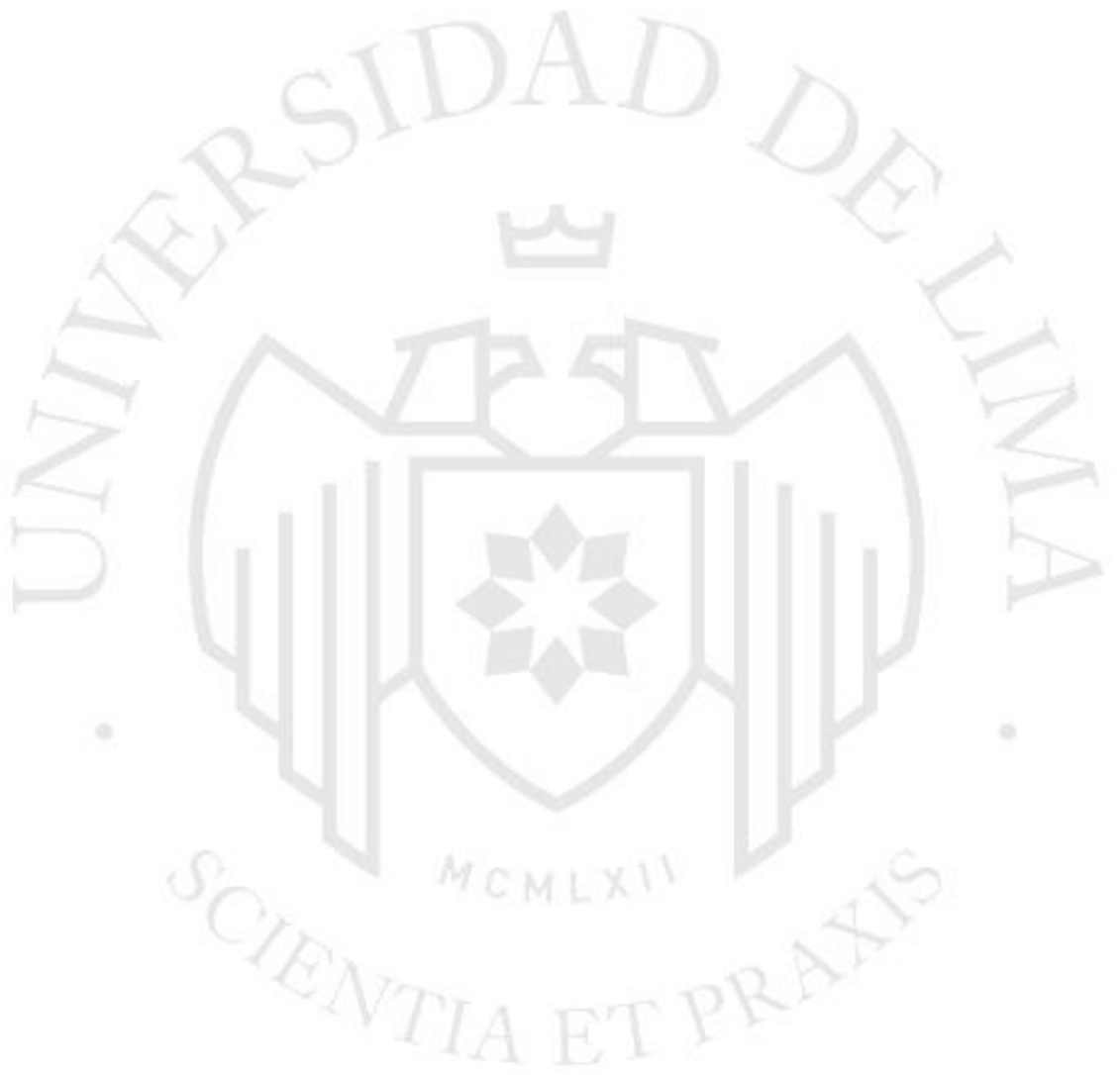




\section{DISIDENCIA Y CONCORDANCIA \\ LOS CAMINOS BIFURCADOS DE LA REALIZACIÓN AUDIOVISUAL}




\section{ÍNDICE}

RESUMEN

$\begin{array}{ll}\text { INTRODUCCIÓN } & 6\end{array}$

1. EXPERIENCIA PROFESIONAL

1.1 Ejercicio Laboral. El ámbito institucional - empresarial 9

1.2 Filmografía. El ámbito expresivo - personal 12

1.3 Exposiciones y Muestras $\quad 13$

1.4 Reconocimientos Obtenidos $\quad 14$

2. COMPETENCIAS PROFESIONALES 16

2.1 Caso 1. Video institucional del programa

Liderazgo para la Transformación

2.2 Caso 2. El descubrimiento de las licencias y rupturas.

Tantear la experimentación a mediado de los 90

2.3 Caso 3. La visualidad no es un estado de gracia.

Resistir en fragmentos los primeros dosmiles $\quad 24$

3. REFLEXIONES PROFESIONALES 28

3.1 Reflexiones, aprendizajes 28

3.2 Información universitaria útil en el desarrollo profesional $\quad 29$

3.3 Cambios tecnológicos que han impactado 29

3.4 Recomendaciones 30

$\begin{array}{ll}\text { ANEXOS } & 32\end{array}$ 


\section{RESUMEN}

\section{RICARDO ARTURO AYALA ROJAS.}

Bachiller en Ciencias de la Comunicación de la Universidad de Lima, con especialidad en Medios Audiovisuales.

Me desempeño profesionalmente en distintas áreas de la producción audiovisual: guion, cámara, dirección y edición. He realizado proyectos en diversos formatos del cine, el video y la televisión, tales como documentales, ficciones, notas periodísticas, telenovelas, miniseries, etc.

Ejercí la docencia como Jefe de Prácticas en la Universidad de Lima y como profesor en el Instituto de Diseño y Comunicación Toulouse Lautrec.

Desde el año 2000 empecé a trabajar de manera independiente en el campo institucional y documental, como contratado por empresas productoras.

A través de los años he llevado una práctica constante como director, camarógrafo y editor, lo que en el medio se reconoce bajo el nombre de Realizador, participando directamente en todas las áreas del proceso: pre producción, producción y post producción.

Esta labor ha retribuido en mi comprensión y manejo del oficio, desde la práctica con las máquinas y la tecnología hasta lo semántico de cada imagen propuesta. Pasando por la organización, logística y el lado mas artesanal del proceso.

En el año 2007 creé mi propia empresa de producción, Masmédula Comunicación S.A.C., a través de la cual llevo a cabo proyectos encargados por empresas e instituciones públicas y privadas, nacionales o extranjeras.

En paralelo he realizado proyectos personales en las áreas del documental y la ficción. 


\section{INTRODUCCIÓN}

Bachiller en Ciencias de la Comunicación de la Universidad de Lima, con especialidad en Medios Audiovisuales. Me desempeño profesionalmente en distintas áreas de la producción audiovisual: guion, cámara, dirección y edición.

A lo largo de mi carrera he participado en proyectos para cine, video y televisión.

\section{FORMACIÓN}

\section{UNIVERSIDAD DE LIMA.}

Bachiller en Ciencias de la Comunicación.

Especialidad de Medios Audiovisuales.

\section{ALIANZA FRANCESA DE LIMA.}

Idioma Francés.

Nivel 6to Intermedio

\section{ÉCOLE SUPÉRIEUR DES ARTS DÉCORATIFS DE STRASBOURG. FRANCE}

Stage

Group Art3, Atelier "Yeux (et oreilles) VIDEO"

\section{AUTODIDACTA}

Edición No Lineal:

Avid Media; Final Cut Pro; Adobe Premiere Pro.

Post Producción de Video:

Adobe After FX.

\section{Post Producción de Sonido:}

Adobe Audition.

\section{Operador de Cámaras:}

Cámaras de cine $16 \mathrm{~mm}$

Camcorders de video de formatos análogos

Camcorders profesionales de video de formatos digital en cinta

Camcorders de video en formato HD 
Cámaras DSRL

Cámaras de cine digital

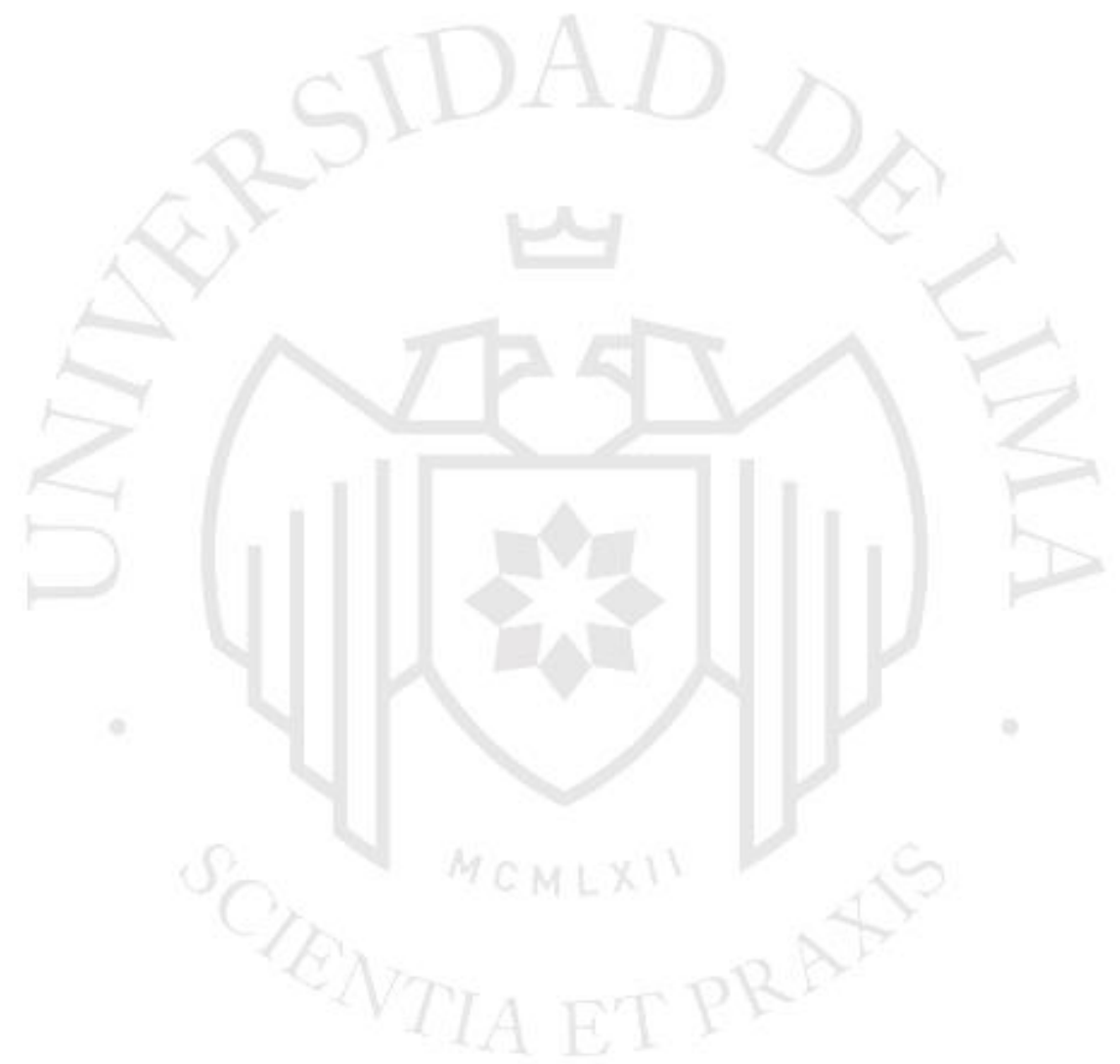




\section{EXPERIENCIA PROFESIONAL}

Desde el año 2007 tengo mi propia empresa de producción audiovisual: MÁSMÉDULA COMUNICACIÓN S.A.C. A través de ella recibo encargos de distintas instituciones, ONGs o empresas, para realizar las propuestas audiovisuales que surgen de sus necesidades comunicativas.

Mi labor parte desde la realización, orientada a dirigir el proceso de desarrollo del producto audiovisual a través de sus distintas etapas: Pre producción, Producción y Post producción.

En el mundo de los mensajes audiovisuales, las empresas e instituciones siempre han buscado la construcción de su imagen. Ya sea para difusión o sólo como una reafirmación, el relato audiovisual es una manera de demostrar su existencia.

Si bien hace no muchos años los altos costos del celuloide como soporte audiovisual alejaban a las empresas de la posibilidad de llevar a cabo sus propias narraciones o mensajes, con la popularización del Video y sobre todo de los formatos caseros considerados como menores e imperfectos (camcorders S-VHS, HI8, MiniDV) se consolida un nuevo mercado comunicacional en donde el producto es el relato institucional que usa como soporte un mensaje de video.

El nuevo soporte empezó a otorgar la posibilidad de comunicación a las organizaciones y es así que se establece una nueva demanda. Desde entonces se desarrolló una gran producción de mensajes institucionales a pesar de que el ámbito de difusión de los mismos era limitado y dependía del tiraje de copias que se mandaban hacer.

En la actualidad con el Video HD y las facilidades de producción que suponen las nuevas tecnologías, todo es posible. Es importante mencionar que los formatos han mutado y se han adaptado, debido sobre todo a las nuevas formas de consumo que se establecen a partir de la aparición del internet y las redes sociales como plataformas de exhibición y difusión en el cyber espacio.

En el inicio de mi carrera la popularización del video me ofreció la oportunidad de ingresar al mercado laboral-organizacional pero a la vez, me otorgó la posibilidad invalorable de construir imágenes desde mis inquietudes creativas personales.

Sin estos formatos caseros, aquellos que se tildaban de "menores", no hubiese sido posible para mí hallar un medio de expresión, dónde a través del ensayo y la práctica encontré un camino para mi desarrollo audiovisual. 
De esa manera el video, permitió que mi labor como profesional de la comunicación se dividiera siempre en dos ámbitos que me atrevería a clasificar de la siguiente manera:

-El ámbito institucional-empresarial.

-El ámbito expresivo-personal.

La siguiente compilación es un repaso de mi experiencia profesional y está presentada bajo la señalada clasificación.

\subsection{EJERCICIO LABORAL \\ El ámbito institucional - empresarial}

UNIVERSIDAD DE LIMA.

Asistente de iluminación. Miniserie "Tradiciones Peruanas"

Formato: Betacam

Febrero 1994.

UNIVERSIDAD DE LIMA - PANORAMA PRODUCCIONES.

Asistente de sonido. Mediometraje "Aura".

Formato: $16 \mathrm{~mm}$

De Marzo a Abril 1994.

PANAMERICANA TELEVISION

Asistente de cámara. Miniserie "El Espejo de mi Vida".

Formato: Betacam

De Julio a Agosto 1994.

IGUANA PRODUCCIONES. Lima Perú.

Asistente de sonido. Piloto de miniserie televisiva "Cazadores de Noticias"

Formato: Betacam

Marzo 1995.

PANAMERICANA TELEVISION. Lima Perú.

Editor del área de noticias.

De Abril a Junio 1995.

PANAMERICANA TELEVISION. Lima Perú.

Asistente de Sonido en la telenovela "Gorrión".

De Julio a Agosto 1995.

UNIVERSIDAD DE LIMA.

Jefe de Prácticas en la Facultad de Ciencias de la Comunicación, en los Cursos de: Taller de Cine I y Equipos Audiovisuales. 
De 1995 a 1997.

ONG - CEAPAZ

Camarógrafo del documental "Jóvenes y Héroes".

Formato: S-VHS

Julio 1999.

UNIVERSIDAD NACIONAL SAN CRISTOBAL DE HUAMANGA.

Realización de: Taller Experimental en video, CAJA NEGRA.

Octubre 1999.

GUARANGO CINE Y VIDEO.

Camarógrafo y Editor en proyectos audiovisuales.

De 1999 a 2001.

INSTITUTO DE DISEÑO Y COMUNICACIÓN - TOULOUSE LAUTREC.

Profesor en los cursos: Edición y Dirección Fotográfica.

De 1999 a 2000.

INSTITUTO DE ESTUDIOS PERUANOS - IEP

Realización del Documental: Músicos Andinos en Lima, tradición y modernidad.

Formato: MiniDV

Junio 2002.

OFICINA NACIONAL DE PROCESOS ELECTORALES (ONPE).

Realizador de videos institucionales y educativos en el área de comunicaciones perteneciente a la GERENCIA DE INFORMACION.

Formato: MiniDV

De Julio 2002 a Diciembre 2004.

CENTRO DE PROMOCIÓN Y DESARROLLO POBLACIONAL (CEPRODEP)

Realizador de Documentales: Difundiendo la Verdad. // Mujeres en la Guerra, Violencia Sexual y Secuelas de guerra. // Violencia a Puerta Cerrada.

Formato: MiniDV

De Febrero 2004 a Febrero 2005.

RED DE ENERGÍA DEL PERÚ (REP)

Producción y Realización de Documental Institucional: ¿Qué está pasando en el Perú?. Formato: MiniDV

De Febrero a Mayo 2006

PRIMERA NOCHE EN BLANCO DE LIMA

(PROYECTO DELIVERI, POLÍTICAS DE INTERCAMBIO)

Realización de Documental sobre las acciones de los artistas Antoni Miralda y Jota Castro en el marco del evento La Noche en Blanco de Lima.

Formato: MiniDV 
Mayo 2008.

COMPAÑÍA MINERA CERRO VERDE.

Producción y Realización del Documental: Chapi Jardín de la Fe. (Arequipa-Perú).

Formato: MiniDV

De Mayo a Junio 2008.

TERRA NETWORKS PERÚ

Producción y Realización de VIDEO CLIP para banda ganadora del concurso TERRA

ROCK.

Formato: FullHD

2009

MUNICIPALIDAD METROPOLITANA DE LIMA

Realización de videos institucionales para Campañas y Eventos

de la Gerencia de Cultura.

Formato: FullHD

De 2011 a 2014.

ONE BILLION RISING - CAMPAÑA UN BILLON DE PIE, PERÚ.

Realización de videos para difusión y divulgación de la campaña en sus distintas versiones.

Formato: FullHD

De Febrero 2013 a Febrero 2015.

UNICEF - OFICINA REGIONAL PARA AMERICA LATINA Y EL CARIBE (LACRO)

Documental sobre Realidad de los Niños y Niñas en la Amazonía.

Formato: FullHD

Setiembre de 2014.

NAVIERA PETRAL / CORPORACIÓN LUDENS

Realización de Documental Institucional Histórico

sobre la trayectoria de la empresa en el Perú.

Formato: FullHD

Julio 2016.

INSTITUTO DE GOBIERNO DE LA UNIVERSIDAD SAN MARTIN DE PORRES / BANCO DE DESARROLLO DE AMERICA LATINA. (CAF)

Producción y Realización de Documentales para el programa nacional: Líderes para la Transformación.

Formato: MiniDV - FullHD

Desde el 2007 al 2018.

UNICEF - PERÚ

Producción y Realización de Videos (Spots - Documentales - Institucionales) para las distintas campañas de la organización.

Formato: FullHD

Desde el 2013 al 2019. 


\subsection{FILMOGRAFÍA}

\section{El ámbito expresivo - personal}

DOCUMENTAL

Público Cautivo

(largometraje) 2018

Justicia

(cortometraje) 2012

El Niño del Cusco

(largometraje) 2010

Agua Escalera

(cortometraje) 2009

\section{FICCIONES}

Fukin Materia

Biutiful Puta Fortuna

Trinidad

Pública

El Fin de Edmundo

Resta el Vacío

Ensayo sobre la Adaptación

Bendito Seas

Exilio, creo ser (cortometraje)

(cortometraje)

(cortometraje)

(cortometraje)

(cortometraje)

(cortometraje)

(cortometraje)

(mediometraje)

(mediometraje)
2016

2015

2014

2012

2010

2008

2007

1996

1993

\section{EXPERIMENTAL}

Perderte Solo

Adagio

Dolor de orbita

Sonríe

Sangre de grado

2001

Hay veces y nadie

Mamá que linda la casa

Hecho en el Perú

Bebo sopa de sirenas

2002

La telenovelita de las doce

2003

Partir - Dejar

2006

OFF

Sin Pronóstico

2008

\section{VIDEO CLIP - ROCK}

Palpitaciones (Radio Criminal) 


$\begin{array}{lll}\text { Edén } & \text { (Rafo Raez) } & 1996 \\ \text { Don Pedro Marmaja } & \text { (Leusemia) } & 1998 \\ \text { El momento } & \text { (Voz Propia) } & 1998 \\ \text { El piloto } & \text { (Voz Propia) } & 2004 \\ \text { Lentes amarillos } & \text { (Voz Propia) } & 2007 \\ \text { Déjame entrar } & \text { (Manganzoides) } & 2008 \\ \text { Te quiero hoy } & \text { (C-4) } & 2008\end{array}$

\section{VIDEO DANZA}

$\begin{array}{lll}\text { L'Escandale } & \text { (Paris) } & 2005 \\ \text { La Eskina es la misma } & \text { (Paris) } & 2005 \\ \text { Ruta } & \text { (Paris) } & 2005\end{array}$

Algunas de estas obras personales han sido seleccionadas para festivales, exposiciones y muestras de video en espacios de arte.

\subsection{EXPOSICIONES Y MUESTRAS}

ANTIFILMS. Muestra Itinerante de Video Independiente. 1996. (Lima-Perú)

EL ULTIMO LUSTRO. Muestra Colectiva en el C.C. de Bellas Artes. 1998. (Lima-Perú)

1ER FESTIVAL DE VIDEO INDEPENDIENTE.

1999. (Trujillo-Perú)

4TO FESTIVAL DE VIDEO ARTE. Alta Tecnología Andina/URP 2000. (Lima-Perú)

SALÓN REGIONAL LIMA- II BIENAL NACIONAL DEL PERÚ. 2000. (Lima-Perú)

LETEO memoria/olvido. Galería Pancho Fierro-Municipalidad de Lima. 2001. (Lima-Perú)

B\&N Y DE COLOR. Muestra de Video Arte latinoamericano. Centro de Arte Reina Sofía.

2001. (Madrid-España)

PERÚ-RESISTENCIAS. Muestra de Video Contemporáneo de Perú. Museo Casa de América.

2001. (Madrid-España) 
SALÓN DE FINALISTAS DEL CONCURSO: Pasaporte para un Artista.

C.C. de la PUCP.

2002. (Lima-Perú)

MUESTRA DE ARTE PIRATA. C.C. Bellas Artes

2003. (Lima-Perú)

7MO FESTIVAL DE VIDEOARTE. Alta Tecnología Andina. (ATA)

2003. (Lima-Perú)

III FESTIVAL DE VIDEO DANZA. C.C.Rojas.

2005. (Buenos Aires-Argentina)

FESTIVAL DE CINE de LASA,

Selección Oficial con el documental: Mujeres en la Guerra.

2006. (San Juan-Puerto Rico)

MEX PARISMENTAL. Muestra de video experimental contemporáneo.

Studio Galande.

2006. (Paris-Francia)

FESTIVAL INTERNACIONAL DE CINE CONTEMPORÁNEO (FICCO)

Muestra de video danza. Sala Cinemex-Insurgentes.

2007. (MéxicoDF-México)

MEX PARISMENTAL. Muestra de video experimental contemporáneo.

Cinema de La Clef

2008. (Paris -Francia)

11eme FESTIVAL DES CIENMAS DIFFEÉRENTS.

2009. (Paris-Francia)

PROYECTO HELGA. Exposición interdisciplinaria colectiva.

MAC museo de arte contemporáneo de Barranco

20014. (Lima-Perú)

\subsection{RECONOCIMIENTOS OBTENIDOS}

Premio al cortometraje JUSTICIA.

Concurso de Obras Cinematográficas Peruanas de Cortometraje-2012

Ministerio de Cultura del Perú.

Noviembre 2012. 
Premio IBERESCENA 2010 con el colectivo LoQueMePlace.

Estreno julio 2011.

Mejor cortometraje. VIDEO FEST 2007

San Francisco, EE UU.

Setiembre 2007.

2do premio. Concurso Nacional "Pasaporte para un Artista".

Embajada de Francia en Perú.

Agosto 2002.

Beca para la producción de documental antropológico: Músicos Andinos en Lima. Instituto de Estudios Peruanos IEP - Fundación Rockefeller

Mayo-Junio 2002 


\section{COMPETENCIAS PROFESIONALES}

Para este resumen quiero referirme en primer lugar de un caso que pertenece al ámbito institucional-empresarial.

\subsection{CASO 1}

VIDEO INSTITUCIONAL DEL PROGRAMA LIDERAZGO PARA LA TRANSFORMACIÓN

Cliente: Universidad de San Martín de Porres (USMP) - Banco de Desarrollo de América Latina (CAF)

\section{Antecedentes:}

En el año 2006 la CAF establece alianza estratégica con el Instituto de Gobierno y Gestión Pública de la USMP para impartir una capacitación a nivel nacional.

La capacitación está dirigida a líderes naturales de distintas organizaciones sociales, se establecen sedes en distintas zonas del Perú y por un período de 9 fines de semana ( 3 meses aproximadamente) asisten a módulos de enseñanza con el objetivo de prepararlos en temas de desarrollo y gestión de proyectos y gobernabilidad.

El programa se llamó Liderazgo para la Transformación, tuvo su primera versión en 2006 y renovaba convocatoria cada año y duró hasta el 2018 cubriendo casi todas las regiones del Perú.

\section{Objetivos:}

Para el año 2007 el cliente (USMP) necesita evidenciar el éxito de su convocatoria (sobre todo después de la primera versión del programa en el año 2006) y plantea la necesidad de un video, el mismo que se sumará a los informes y balances finales presentados a su socio (CAF).

Se necesitaba trasmitir al público los resultados y la eficiencia de la capacitación a nivel nacional, así como la importancia de los conocimientos que se impartían en los diferentes módulos de capacitación

Se planteó como objetivo principal del video presentar a los alumnos, a esos líderes de organizaciones de base que representan a diversos sectores de sus respectivas regiones y son considerados como potenciales agentes de cambio. Teniendo a los alumnos como protagonistas, podríamos comunicar cómo la capacitación de Liderazgo para la Transformación los ayuda a analizar sus distintos contextos, comprenderlos dentro de la realidad nacional y plantear alternativas de solución y mejoramiento en base a las herramientas de liderazgo.

Definido el objetivo del video se procede a armar una estructura audiovisual de base y se organiza la producción:

-Se evalúan y eligen las sedes representaticas y fechas de visita para el registro. 
-Se realiza la selección de los líderes a participar en el video en coordinación con los encargados de cada sede, poniendo énfasis en que al final la muestra debe representar lo heterogéneo del grupo de alumnos del Programa.

-Se realizan 3 viajes de registro a 3 regiones distintas y en cada sede se aborda a 3 alumnos distintos, que suman un total de 9 casos presentados en el video.

\section{Material Producido:}

El producto es un video de corte documental de 17 minutos producido en soporte MiniDV.

Para el año 2007 no cabían muchas restricciones en cuanto al tiempo de extensión de los videos y hablar de 17 minutos de duración era considerado como normal en este tipo de productos audiovisuales.

Solo tuvo una fecha de exhibición (ceremonia de gradución y clausura) y se distribuyeron copias en DVD para todas las sedes y autoridades.

Extracto Video 2007: https://vimeo.com/372106589

\section{Resultados:}

La presentación del video fue en la graduación y clausura del Programa del año 2007 y después de eso, la experiencia del video fue tomada como referente y replicada en distintos paises de la región (Venezuela, Bolivia, Ecuador) donde la CAF también desarrolla el mismo Programa de capacitación de líderes. A partir del año 2008 en los países mencionados se empezaron a producir videos similares.

https://www.youtube.com/watch?v=JjfuLht0wgA https://www.youtube.com/watch?v=2xQ1ZVp4Z4M\&t=200s

https://www.youtube.com/watch?v=crTNUfn2HQk https://www.youtube.com/watch?v=4fQv7vbdt4Q

En el Perú, tras volver a ser convocado para la realización de un nuevo video, esta vez de la versión del Programa 2008, se fortaleció y consolidó una relación laboral casi ininterrumpida, llegando a ser convocado para producir el video documental del Programa de Liderazgo de la CAF-USMP hasta su última versión en el año 2018.

\section{Análisis:}

Después de producido el primer video documental, durante los 6 años posteriores (hasta el 2013) el formato del producto siguió siendo practicamente el mismo diferenciándose básicamente en las sedes y los protagonistas. Durante este lapso de años la producción llegó a cubrir 13 regiones del Perú y dentro de cada una conocimos distintos distritos y provincias a través de sus representantes, los alumnos del Programa de Liderazgo. 
Video compilación 2007-2010:

https://www.youtube.com/watch?v=yLVvTsVMA2A

En paralelo apresurados cambios ocurrían en el contexto de la internet que influyeron en el mundo del video de manera significativa. Alrededor del 2008 la plataforma de Youtube (creada en 2005) había multiplicado su alcance y popularidad debido a su asimilación por parte de Google Inc. y desde entonces más público tenía acceso para abrir cuentas, crear canales y difundir lo que deseen desde el dispositivo que prefieran. El crecimiento de esta plataforma se hizo exponencial.

En el Perú a partir del 2011 los videos del Programa Liderazgo para la Transformación empiezan a ser difundidos a través de un canal propio creado en Youtube y se encontró así una nueva vía de distribución, cuya duración disminuyó a 12 minutos, lo cual para las características del consumo en esta plataforma era un tiempo ideal.

Video 2012

Extracto: https://vimeo.com/372108168

Video completo

https://www.youtube.com/watch?v=ow5K883jJVA\&list=LLSgzRWy1WG vNxt172aMcfLw

Video 2014

Extracto: https://vimeo.com/372110687

Video completo:

https://www.youtube.com/watch?v=LKGkUHOXG8A

Desde el año 2015 la estructura de nuestro producto audiovisual encargado por la capacitación USMP-CAF fue mutando poco a poco por las siguientes motivos:

En primer lugar se redirige el interés hacia los protagonistas, enfocándose en alumnos egresados, dado que interesaba más hacer una especie de seguimiento y observación de los alumnos de promociones anteriores que estaban ahora inmersos en la gestión de desarrollo, para proponerlos como ejemplos a las promociones nuevas.

Video 20015

Extracto: https://vimeo.com/372112664

Video completo:

https://www.youtube.com/watch?v=j0UCLV6B3Pk

En segundo lugar, el consumo de información (sobre todo audiovisual) en redes digitales establece la inmediatez y por consecuencia la necesidad de mensajes comprimidos. Sobre todo, a partir de la popularización de los videos PlayGround en la plataforma de Facebook (alrededor del 2014), queda marcado un nuevo estándar. 
Esto coincide con cambios en la estrucutra de los videos documentales del Programa, a partir de la versión 2016 se empiezan a producir ya no solo un video, sino que se hacen dos de 3 minutos cada uno incorporando además, información escrita en animación y otras características adoptadas de alguna manera del popular formato Playground.

Aunque el foco del interés no cambió (seguía concentrado en evidenciar la carrera de los egresados en sus campos de gestión) el diseño de la estructura adoptada apartir de los mensajes comprimidos dio como resultado relatos cortos (4 minutos en promedio) para su consumo en las nuevas plataformas.

https://vimeo.com/196747260 https://vimeo.com/195365374

https://vimeo.com/245271427

https://vimeo.com/245384363

https://vimeo.com/249410093

El último video producido para el año 2018 rompió este diseño, lo que se hizo fue un video de recuento, un relato donde se compilaban los años de la capacitación de líderes en el Perú y el balance que dejaba la experiencia.

Video 2018. Último video.

https://www.youtube.com/watch?v=oDZw87VwvlY

Los clientes empiezan a considerar la importancia del reporte de audiencia que dictan los nuevos medios, es decir, cuántas personas ven o consumen su mensaje envasado en un video que cuelga de determinada plataforma de difusión, algo que se hace relativo pues entre las principales (Youtube, Facebook, Twitter, Instagram) que compiten, cada una tiene diferencias en su contabilización y mientras que Youtube contabiliza vistas apartir de los 30 segundos, Facebook lo hace a partir de solo 3 segundos.

Lo cierto es que en la actualidad, ha quedado establecido a partir del análisis de esta estadística, que la retención de la audiencia depende significativamente de la duración del video. Con esta premisa, para capturar el interés de la audiencia se debe ingresar a estos medios con el parámetro de: cuanto mas rápido mejor. Esta sería una fórmula para captar mayor audiencia.

Esta tendencia de consumo determina la elaboración de los mensajes de tal manera que en la actualidad, un cliente puede necesitar determinado video pero a la vez requerir distintas versiones del mismo, adecuándolo(s) a la plataforma donde requiera exhibir su mensaje.

Al respecto pongo como otro ejemplo el trabajo que vengo realizando desde hace 6 años con otra institución llamada UNICEF-Perú y que hace evidente esta tendencia en la adecuación a las plataformas digitales de exhibición. 
Hace 7 años (en el 2012), los videos que normalmente encargaban tenían una duración de 5 minutos aproximadamente.

\section{https://www.youtube.com/watch?v=65tlpW2LjXM https://www.youtube.com/watch?v=qnu4XTI76Lk}

Actualmente el video para un determinado tema es encargado y propuesto para tener un tiempo de duración de 2,15 minutos (aproximado), a la vez que se pide versiones específicas para Twitter o para Instagram, siendo que cada una de estas plataformas demarcan especificaciones de tiempo máximo de duración o de aspecto de la imagen (rectangular o cuadrada).

https://www.youtube.com/watch?v=BANd gpYC6A\&t=13s

https://www.youtube.com/watch?v=GnuJMFQBQMM

https://www.youtube.com/watch?v=YYDQbHOkhOl

https://www.instagram.com/p/BxalVbYhpMS/

https://www.facebook.com/unicefperu/videos/359004198302093/

Como comentario final a esta capítulo, quiero mencionar que los productos audiovisuales encargados por instituciones $y / 0$ empresas son necesarios dentro de su dinámica de comunicación externa e interna y son ellas quienes establecen su objetivo. La tarea que los realizadores hacemos es ayudarles a encontrar el camino y la forma en que ese objetivo se materialice en un relato audiovisual eficiente. Entre los principales productos de este tipo están los videos para ventas en ferias o mercados, las videomemorias, los videos de responsabilidad social, los de capacitación e inducción, etc.

Para continuar este breve archivo de mi vida audiovisual, quiero virar la mirada hacia un conjunto de productos que no surgen por encargo ni de una relación contractual-laboral. Las obras que nacen desde la motivación y la búsqueda personal y que han estado presentes en paralelo a todos los años de mi actividad profesional.

Para empezar, es necesario retroceder en el tiempo a la mitad de los años noventa.

\subsection{CASO 2}

EL DESCUBRIMIENTO DE LAS LICENCIAS Y RUPTURAS. Tantear la experimentación a mediado de los 90.

Cliente: Miriam Reátegui (actriz)

\section{Antecedentes:}

Estamos a mediado de los noventas y mi panorama sobre los medios audiovisuales alojaba básicamente lo que venía del mundo estándar de los 
mensajes publicitarios, las pautas televisivas y la tradición cinematográfica convencional.

Había leído de manera limitada sobre posturas disidentes pero nunca había visto ejemplos de nada parecido, hasta que en 1994 asistí durante varias fechas a una muestra de Cine Experimental Alemán en la Universidad de Lima y es ahí que por primera vez experimento como espectador con diversos artefactos audiovisuales atípicos.

En 1995 soy convocado por primera vez para realizar un audiovisual fuera de los ámbitos universitarios. La pieza que me encargaron crear debía "acompañar" una interpretación escénica unipersonal que combinaba danza y teatro, un ensamble recurrente y conocido en aquella época bajo la denominación de: espectáculo multimedia.

\section{Objetivo:}

Proponer imágenes que acompañen y sumen significado a algo que estaba delimitado desde los códigos de la escenificación. Con eso claro, yo debía encargarme del respaldo visual y para realizar mi labor recibí como insumo un extenso poema llamado "Oración para no Perderte" (Mary Soto Limpios de Tiempo).

Inmediatamente identifiqué dos cosas: no me gustaba la propuesta escénica ni el poema en el que se basaba todo. Se hablaba del tema del desamor y la separación desde un lenguaje considerablemente melodramático y a pesar de eso asumí la responsabilidad de haber sido convocado. Pronto tuve claro que mi deseo era abordar la temática del poema pero desde un lado menos conspicuo.

\section{Material Producido:}

Inicialmente se trataba de un material audiovisual de 14 minutos que servía para una proyección a gran escala sobre el fondo de un escenario. El tiempo de duración estaba supeditado a lo que se necesitaba que dure con respecto a la escenificación.

Posteriormente depuré el material, eliminando sobre todo partes demasiado largas y repetitivas, le puse un título y añadí créditos, el resultado fue mi primer trabajo producido de inspiración personal. Se llamó Perderte Solo (1995 / S-VHS ( $7 \mathrm{~min})$

Ejemplo1.

Extracto: https://vimeo.com/372114638

Completo: https://www.youtube.com/watch?v=F8Qswwo9QZk 
Trabajé sin historia ni guión, solo con la idea de proponer algunas imágenes aleatorias para luego colapsarlas, buscando revertir los campos significativos que delineaba el poema que generó este trabajo.

Grabé en dos días con cámara prestada en un estudio a manera de laboratorio de ensayo y el primer material lo edité en tres días en una isla de edición analógica.

\section{Resultados:}

Objetivamente, el producto audiovisual no cumplió cabalmente con la intención de "acompañar" lo escénico porque no se sumaba de manera amable al corpus general de la obra multimedia sino que hacía ruido, era disonante y desconcertaba.

A pesar de su fallido resultado inicial considero este primer trabajo como un catalizador, pues me sirvió para probar la ruptura y el error; ensayar la atemporalidad y el discurso no narrativo; privilegiar la irrupción arbitraria en vez de la continuidad; encontrar belleza en las fallas técnicas así como no temerle a la apropiación y reutilización de material existente. En conclusión, había salido sin proponermelo a pasear por el lindero experimental.

Desde entonces, todos los proyectos personales que pude realizar en los años siguientes continuaban de alguna manera afirmando mi opción de experimentación, vinculada al discurso no narrativo ni lineal.

El video a diferencia del material filmico suponía un soporte inmediato, ofreciéndose además como una herramienta asequible. Estas dos cualidades fundamentales hicieron que automáticamente lo adopte como mi medio de trabajo y expresión.

A mediados de los noventas mi militancia en el video clip fue inmediata puesto que lo entendí como un "género" libre; un medio abierto a la exploración o los ensayos. Esta militancia duró varios años y me dió la oportunidad de practicar dado que siempre se trataba de proyectos autofinanciados con bandas de música afín a mis gustos, por lo que el trabajo se hacía muchas veces (casi todas) con equipos prestados y cero presupuesto.

En el año 2008 luego de haber realizado varios videoclips y colaborado en otros tantos, ocurrió algo que hasta entonces nunca me había pasado. La empresa Terra Networks Perú, me contrata para dirigir un videoclip y por primera vez cuento con un generoso presupuesto de producción. Casualmente luego de terminar el producto decidí no hacer más videoclips, por razones de saturación con el "género".

Ejemplo2.

Extracto: https://vimeo.com/372116023

Completo: https://www.youtube.com/watch?v=isNBw-IATSC 
Ejemplo3.

Extracto: https://vimeo.com/372117238

Completo: https://www.youtube.com/watch?v=sXA8IWpMROU

Ejemplo4.

Extracto: https://vimeo.com/372130600

Completo:https://www.youtube.com/watch?v=m6Je0Fk1RCQ\&list=RD $\underline{\mathrm{m} 6 \mathrm{Je} 0 \mathrm{Fk} 1 \mathrm{RCQ} \& \text { start } \text { radio }=1 \& \mathrm{t}=12}$

A pesar de que mi aspiración de realizador estaba activa gracias a la práctica constante en la realización de videoclips, también trataba de realizar obras narrativas. Por eso escribía guiones y trataba de realizar cortometrajes, esto último con menos frecuencia pues suponía una mayor complejidad de producción y mayores necesidades. Pude realizar alguno y aún cuando sabía que quería contar una historia de manera muy convencional, no podía evitar echar mano de recursos -mañas- anteriormente ensayados, sobre todo en la edición.

Ejemplo5.

Extracto: https://vimeo.com/372132096

Quizás lo que más colmó por esos años mis expectativas de realizador, fue en una serie de videos que empecé a producir, cuya característica común era el no tener un guion escrito. A veces, en lugar de escribir escenas y diálogos, dibujaba y hacía anotaciones para que luego esas imágenes se organizaran creando un relato libre.

Ejemplo6.

Extracto: https://vimeo.com/372133544

Completo: https://www.youtube.com/watch?v=u1v40y2bCAl

Ejemplo7.

Extracto: https://vimeo.com/372134294

Completo: https://www.youtube.com/watch?v=hwqjQRvgGGM

Análisis:

Desde el momento en que intenté formular un relato audiovisual propio percibí que me tomaba muchas licencias y que mi lógica discursiva estaba llena de rupturas, es por eso que tiendo un puente hacia las posturas experimentales donde hallo puntos en común y aterrizo en un nuevo espacio de encuentro que también era visitado por personas provenientes de otras disciplinas. Es ahí donde por primera vez escucho mencionar la palabra "videoarte".

Si bien todos compartíamos como soporte la imagen en video, mi acercamiento a lo experimental no era el mismo que el de un pintor con formación en artes plásticas, quien posiblemente haya preferido concebir su propuesta manipulando la tecnología del video, mi búsqueda de 
experimentación se dirigió a repasar la gramática audiovisual en un intento por justificar mi propio discurso.

\subsection{CASO 3}

\section{LA VISUALIDAD NO ES UN ESTADO DE GRACIA. Resistir en fragmentos los primeros dosmiles.}

En este caso quiero referirme no a una obra en especial, sino a un conjunto de producciones que comparten similares características y que se desarrollaron en un periodo que comprende la primera década del nuevo milenio.

\section{Antecedentes:}

En el año 2000 la ruta que seguían mis intenciones de autor-realizador había quedado trazada y se decantaba por el lado no narrativo. Empecé no a escribir guiones sino a pensar imágenes y con esto, a tratar de construir una visualidad de fragmentos e ideas que no eran necesariamente historias sino que se acercaban muy intuitivamente a sensaciones.

Debo mencionar en honor a la verdad, que sí escribía guiones de historias que quería contar, pero que dificilmente podía concluir y menos, llevar hasta a la realización. Las unicas obras que llegaba a materializar con relativa facilidad y frecuencia eran las piezas de video surgidas desde la busqueda experimental.

\section{Objetivos:}

-Entender, aceptar y dialogar con la sintaxis de mis propios relatos.

-Asumir esas producciones como una búsqueda solitaria y una posibilidad de expresión personal.

-Asimilar un modo de producción independiente, modesto y autogestionario que a la vez convocaba el interés de espacios dedicados al arte, los mismos que se convirtieron en potenciales exhibidores en el marco de una tendencia global que sostenía mi producción y le daba validez a mi trabajo.

\section{Material producido y resultados:}

Un conjunto de alrededor de 15 trabajos, la mayoría relatos audiovisuales hechos para ser mirados, es decir pensados para su consumo bajo condiciones típicas de una proyección, ya sea en pantalla grande o en monitor. Todas estas producciones tuvieron como ámbito de exhibición muestras colectivas y festivales en museos y galerías de arte a los cuales era convocado. En algunos casos, una misma obra tenía un recorrido por diversos destinos y finalmente podía acabar compilada en catálogos y archivos. 
Algunas de esas producciones recibieron premios de reconocimiento. Ejemplos:

\section{Sonrie}

4TO FESTIVAL DE VIDEO ARTE. Alta Tecnología Andina/URP

2000. (Lima-Perú).

B\&N Y DE COLOR. Muestra de Video Arte Latinoamericano.

Centro de Arte Reina Sofía. 2001. (Madrid-España)

Ejemplo8.

Extracto: $\underline{\text { https://vimeo.com/372135547 }}$

Sangre de grado (video instalación)

SALÓN REGIONAL LIMA- II BIENAL NACIONAL DEL PERÚ.

2000. (Lima-Perú)

Ejemplo9.

Extracto: https://vimeo.com/372139638

\section{Mamá que linda la casa}

PERÚ-RESISTENCIAS. Muestra de Video Contemporáneo de Perú.

Museo Casa de América. 2001. (Madrid-España)

Ejemplo10.

Extracto: https://vimeo.com/372137535

Completo: https://www.youtube.com/watch?v=vrRyxThMy6s

\section{Hay veces y nadie}

LETEO memoria/olvido. Galería Pancho Fierro-Municipalidad de Lima. 2001. (Lima-Perú)

Ejemplo11.

Extracto: $\underline{\text { https://vimeo.com/372138561 }}$

\section{Bebo sopa de sirenas}

SALÓN DE FINALISTAS DEL CONCURSO: Pasaporte para un Artista.

C.C. de la PUCP. 2002. (Lima-Perú).

Ganador de 2do Premio.

Ejemplo12.

Extracto: https://vimeo.com/372140842

Completo: https://www.youtube.com/watch?v=WJmBQdW3K5o\&t=12s

\section{Off}

CENTRO CULTURAL DE ESPAÑA. 2006. (Lima-Perú)

Ejemplo13.

Extracto: https://vimeo.com/372141450

Completo: https://www.youtube.com/watch?v=eC79VnEL2_M

\section{Sin Pronóstico}

VIDEO FEST 2007. San Francisco, EE UU.

Ganador de premio a Mejor cortometraje. 
Ejemplo14.

Extracto: https://vimeo.com/372142419

Completo: https://www.youtube.com/watch?v=r9bNg2TuZ6A

\section{Análisis:}

Si bien es cierto que mis producciones deambularon por el lado del arte, quiero decir que siento que nunca me convertí en un artista audiovisual o video artista.

Un día ubicado entre el público que asistía a una muestra me di cuenta de que todo lo que producía era tributario del cine: mis videos se veían en una pantalla, en una proyección a oscuras, con un público sentado y pasivo que llegaba al espacio de exhibición con la única consigna de entregarse a los estímulos de la visualidad y sonoridad.

Aunque siempre haya intentado revertir la gramática del cine solo formulé relatos llenos de recursos híbridos pero que siempre conservaban un horizonte narrativo.

Comprendí entonces que el cine nunca había salido de mi y decidí cambiar de rumbo para buscar una posibilidad de reencuentro.

Quisiera finalizar este repaso de mi carrera mencionando que aproximadamente desde finales de la década (2010) y hasta la fecha (2019), todos los proyectos que he producido han tomado el camino de retorno al cine narrativo. El tránsito no ha sido inmediato ni radical porque la herencia o legado que me dejan los años de paso por la disidencia narrativa es irrevocable y aflora como un lapsus, casi como una segunda lengua materna con la cual me siento a gusto.

A continuación, algunos ejemplos de producciones de la última década.

Ensayo sobre la Adaptación

(cortometraje)

Ejemplo15.

Extracto: https://vimeo.com/372143250

Completo: https://vimeo.com/8129767

El Fin de Edmundo

(cortometraje)

2010

Ejemplo16.

Extracto: https://vimeo.com/372144048

Completo: https://vimeo.com/16974393

Trinidad

(cortometraje)

2014

Ejemplo17.

Extracto: https://vimeo.com/372145213

Completo: https://vimeo.com/102954422 
Ejemplo18.

Extracto: https://vimeo.com/372146231

Completo: https://vimeo.com/214074419

\section{Justicia}

(cortometraje)

2012

Ejemplo19.

Extracto: https://vimeo.com/372147426

Completo: https://vimeo.com/36621070

El niño del Cusco

(largometraje)

2010

Ejemplo20.

Extracto: https://vimeo.com/372148515

Completo: https://vimeo.com/35059151

Público Cautivo

(largometraje)

2018

Ejemplo21.

Extracto: https://vimeo.com/369957991 


\section{REFLEXIONES PROFESIONALES}

\subsection{REFLEXIONES Y APRENDIZAJES:}

No hay una definición que pueda ayudar a delimitar el cine experimental, es inútil intentar encasillarlo bajo una sola sentencia. No obstante, sí es posible entenderlo a partir de lo que no es: no narración, no ficción, no industria, etc. Se puede también reconocerlo por características que contrastan o difieren respecto de un sistema convencional que lo origina y del cual trata de distanciarse, que en este caso vendría a ser el cine narrativo.

El termino videoarte supone un cambio hacia la tecnología del video pero con la misma dirección explorativa. La imagen electrónica y posteriormente la imagen digital, trajeron resultados inéditos que fueron sumándose a la disidencia narrativa y que hoy constituyen el acervo de una cultura experimental.

El consumo de productos alternativos como el cine experimental siempre ha convocado a un público selectivo reportado en cantidades limitadas con respecto al cine convencional. Es cualitativo versus cuantitativo, pero convoca de todos modos.

Mi opción y recorrido por lo experimental nació de mi propia incapacidad narrativa. En un determinado momento, muy al inicio de mi carrera, reconocí que la lógica con la que mi cabeza organizaba secuencias con la intención de narrar estaba llena de cortes abruptos y relaciones aleatorias aparentemente arbitrarias. Esa fue la manera como mis propias falencias produjeron su discurso, arrastrando mis limitaciones y usándolas para definir una sintaxis personal.

Es importante que cada realizador reconozca y asimile sus lógicas discursivas propias, que las trabaje y las afine. Con eso alimentará su propia y única narrativa. A veces, buscar identificarse con el patrón convencional puede ser limitante o simplemente estéril.

Adoptar el modo de producción independiente desde el video fue fundamental para sostener una continuidad, y este modo de producción a su vez, fue posible gracias al desarrollo y evolución en tecnologías de registro y edición.

Las circunstancias que abrieron el universo a potenciales generadores de material audiovisual fueron la popularización de cámaras caseras, su evolución y mejoramiento constante -desde el soporte VHS hasta la tecnología digital-, sumado al procesamiento de datos a través de softwares de edición asequibles que cualquier mortal que tuviera acceso a una computadora personal.

La ecuación del modo de producción independiente se había completado: de un lado tener ideas para realizar $y$ del otro tener medios a la mano para 
realizarlas. Esto dio como resultado productos personales y la posibilidad de desarrollar una producción continua.

\subsection{INFORMACION UNIVERSITARIA ÚTIL EN EL DESARROLLO PROFESIONAL.}

Considero como un hito importante remanente de la formación el tener siempre una apreciación crítica del cine, saber que el discurso cinematográfico, al margen de ser personal o industrial, abstracto o evidente, siempre abre un proceso comunicativo $\mathrm{y}$ es entonces fundamental entenderlo como una instancia significante.

Entender sobre la morfología del cine y además de los aspectos técnicos que la determinan, asi como la tecnología disponible para producir, es también información adquirida durante los años de estudio, que amplia las competencias de cada profesional.

Conocer la gramática cinematográfica es algo que los clientes aprecian; las empresas e instituciones que demandan y encargan trabajos audovisuales esperan ver en sus productos un discurso correcto y convencional. Es imposible que en este ámbito pueda haber cabida a las experimentaciones.

Por último, debo de hacer mención a la importancia de la imagen como centro de todos los estudios visuales (y audiovisuales) por su capacidad de referir o proponer significados y de constituirse en entornos mayores propuestos como visualidad.

\subsection{CAMBIOS TECNOLÓGICOS QUE HAN IMPACTADO.}

La existencia del video como soporte de registro nos sirvió a todos para desarrollar una actividad profesional en el medio audiovisual. No obstante, siempre fue considerado como un formato menor, pues el paradigma era el material filmico, por la riqueza de información lumínica-cromática que le era inherente. Esto que era su principal valor, fue también su mortal desventaja; el fílmico era un medio lejano para cualquiera que no pudiera solventar los altos costos que implicaban producir en cine.

Felízmente, el video nunca paró en su evolución y desarrollo: de la imagen analógica en cinta electromagnética pasamos la tecnología digital y la imagen de alta definición. De las cámaras básicas pasamos a cámaras con un estándar cada vez mas profesional.

Algo que cambió radicalmente la producción fué la aparición de la edición no lineal, previo a esto había que tener acceso a muchos aparatos para poder editar video (una vcr reproductora, una vcr grabadora, un controlador, dos monitores y parlantes. Este era el combo mínimo indispensable). La 
popularización de softwares que procesaban datos digitalmente y convertían una simple pc en una herramienta de edición fue casi como la llegada a la luna.

El video nunca paró su desarrollo a tal punto que desplazó y sepultó al fílmico. Hoy la imagen generada por componentes digitales de alta definicion puede tener tanta riqueza de información como el celuloide. Sin embargo, cabe mencionar que el video de ultra alta definición se desarrolló tanto en la industria audiovisual que actualmente tiene un flujo de trabajo bastante denso y costoso.

En definitiva la aparición de internet es uno de los grandes cambios que hemos presenciado porque redefinió el flujo de la información y la administración de los mensajes. La popularización de plataformas como Youtube o la formación de comunidades a través de redes sociales trajo nuevas nociones de audiencia.

Sumado a todo eso, el progreso de la telefonía movil planteó nuevas segmentaciones de público y consumo, los cuales constantemente determinan cambios en los formatos, sobre todo en los productos audiovisuales.

\subsection{RECOMENDACIONES.}

No existe la obra perfecta ni tampoco las condiciones ideales para producir. De lo que se trata la carrera profesional es de producir, y para esto habrá que lidiar con elementos adversos. Estos pueden venir desde el entorno, el contratante (si es un trabajo por encargo) o de uno mismo.

Si se trata de una obra por encargo, nuestro trabajo debe dar por resultado aquello que mas se parece a la idea de quienes la concibieron (aunque haya veces en las que uno no necesariamente concuerde con eso). Si se trata de una obra personal será necesario evaluar qué tanto del resultado se parece a lo ideado por nosotros mismos y si no se parece, hasta qué punto podemos reconocer que la obra está terminada.

Es primordial que haya una planificación y diseño que organicen todo, pero debemos tener en cuenta que la intromisión del azar demanda de la capacidad de improvisación como herramienta. Una obra sólo existe cuando se realiza.

Es necesario mantenerse activo, ejercer es ensayar, probar, fracasar, acertar. La práctica constante es necesaria como un sinónimo de salud creativa y como el camino seguro a consolidar un oficio. Mejor es tener obras concretas donde uno pueda observar defectos y aciertos que tener obras que sólo se quedan en el mundo de las ideas.

Es importante mantenerse actualizado en la tecnología, sobre todo cuando está en cambio constante y nuestro trabajo se relaciona directamente con ella. También se debe consumir muchos productos audiovisuales con la 
mente abierta a las posibilidades. Mirar y oír evitando la descalificación previa. Consumir todo lo que venga y luego pasar -si se quiere- a ser selectivos. De esta manera podemos tener un panorama fresco del escenario, las propuestas y las tendencias.

Por otra parte, mantenerse actualizado del panorama geopolítico, local y global no es solo importante, sino un deber. 
ANEXOS.

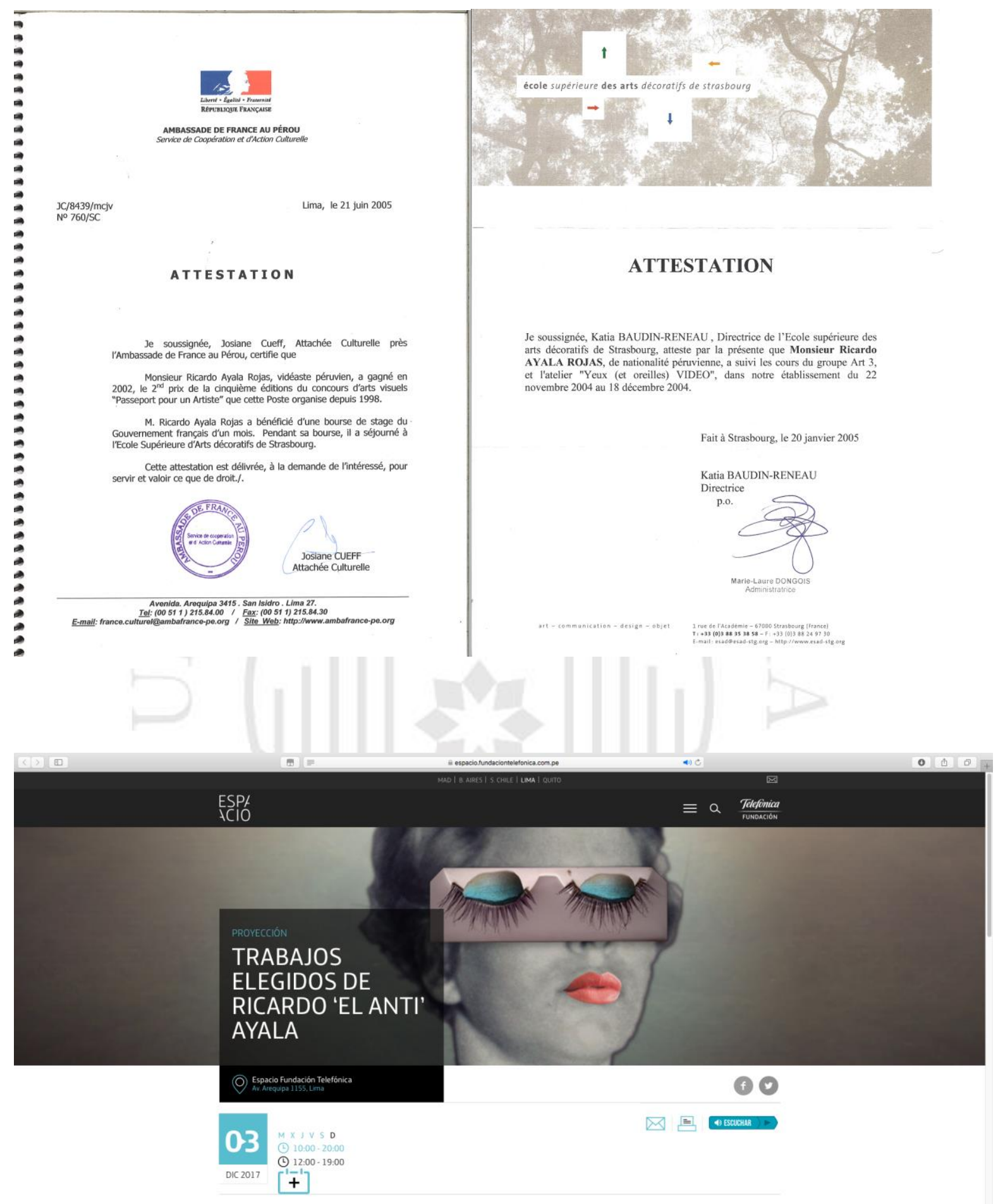

Proyección Transcinema

Trabajos elegidos de Ricardo 'El Anti' Ayala

Domingo 3 de diciembre | 5:00 p.m.

Ingreso libre. No necesita inscripción 


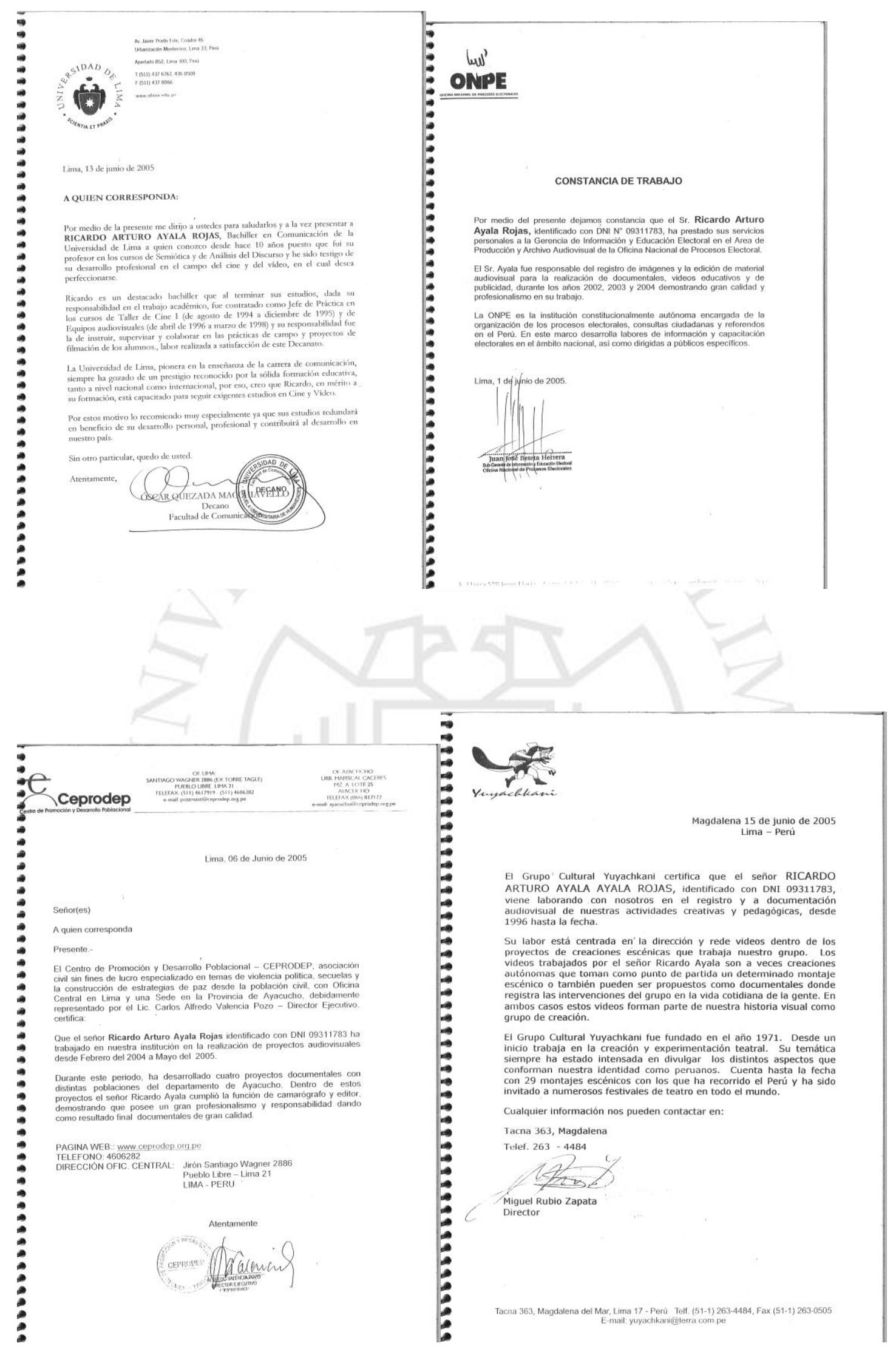


"Año de la lucha contra la corrupción e impunidad"

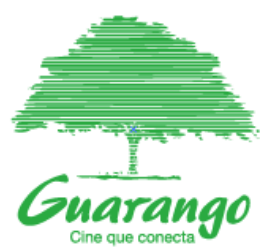

CONSTANCIA DE SERVICIO NO PERSONAL

El Presidente de la Asociación Guarango Cine y Video,

una productora que emplea herramientas audiovisuales para generar cambios en los espectadores por medio de la producción y difusión participativa de herramientas que sensibilicen a la opinión pública nacional e internacional en temas sociales, ambientales, culturales y de derechos humanos, por el presente documento

\section{DEJA CONSTANCIA:}

Que Ricardo Ayala Rojas, con DNI № 09311783, Bachiller en Ciencias de la Comunicación de la Universidad de Lima, con especialidad de Medios Audiovisuales, prestó servicios independientes en nuestra institución, como Camarógrafo y Editor en Proyectos Audiovisuales.

Este trabajo ha sido realizado durante los años 1999 al 2001, logrando demostrar profesionalismo y responsabilidad en el desarrollo de las labores encomendadas.

Posterior al año 2001 ha colaborado eventualmente en proyectos específicos encargados a nuestra institución.

Extendemos el presente certificado para los fines que estime conveniente.

Lima, 11 de noviembre de 2019

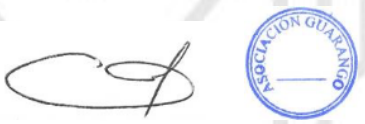

Ricardo Cabellos Damián Presidente

ASOCIACIÓN GUARANGO CINE Y VIDEO

RUC: 20251826774

Jr. Cayetano Heredia 785 int 2 - Jesús María. Lima - Perú

Tel: 4601135 - 


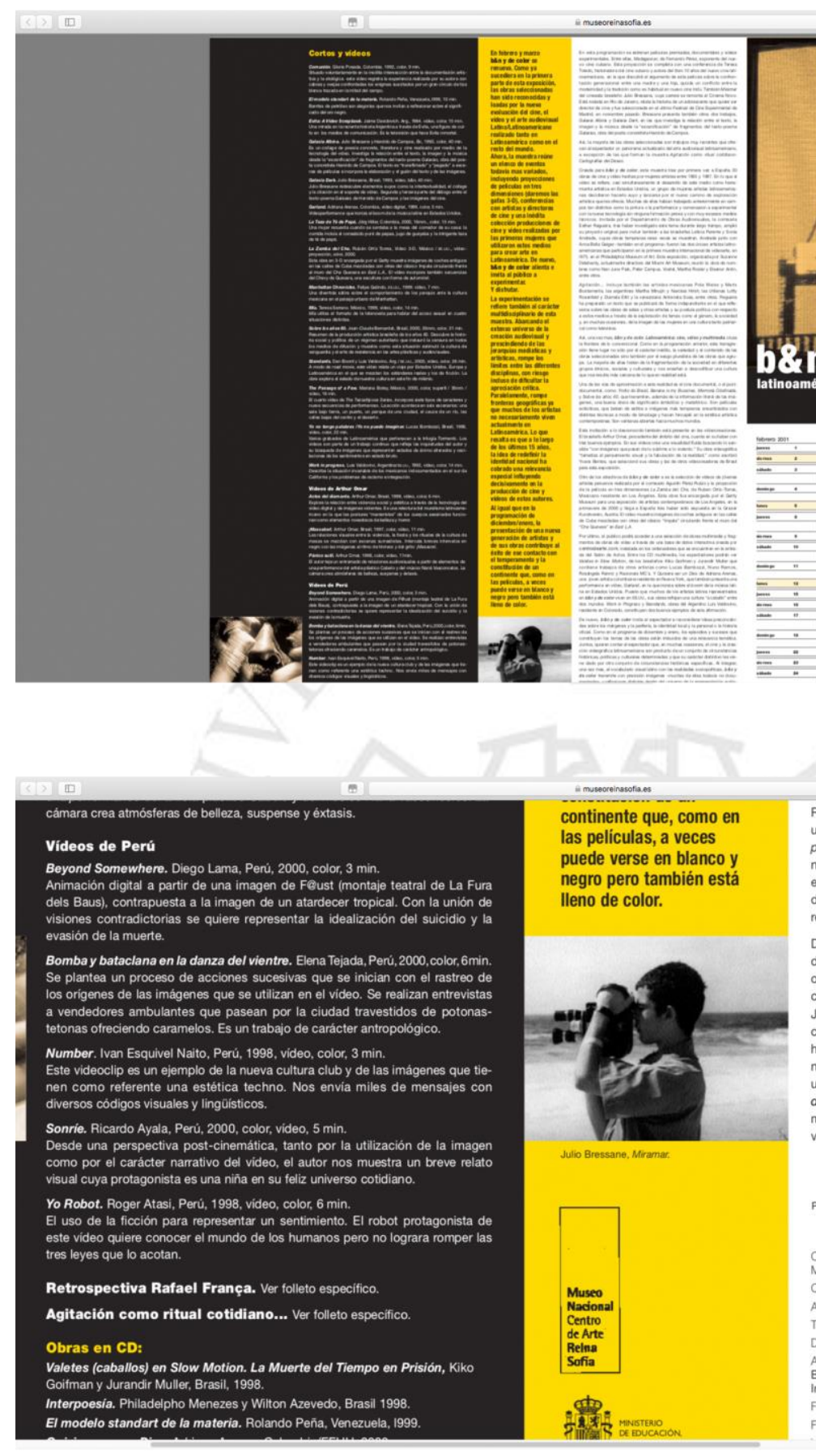

a) 0 a d a Rosángela Rennó y Racionais MC's. Y Quisiera ser un Dios de Adriar una joven artista colombiana residente en Nueva York, que también pre performance en video, Garland, en la que ironiza sobre el boom de la nn na en Estados Unidos. Puesto que muchos de los artistas latinos repr en bany de color viven en EE. UU., sus obras retelejan una cultura "a cat do pesidente en Colorado. consincyen dos buenos ajmplos de esta afirme De nuevo, b\&n y de color invita al espectador a reconsiderar ideas pi das sobre los márgenes y la periferia, la identidad local y la personal o oficial. Como en el programa de diciembre y enero, los episodios y su constituyen los temas de las obras estan imbuidos de una relevancia ción videografica latinoamericana son producto de un conjunto de circa históricas, politicas y culturales determinadas y que su carácter distint e dado por otro conjunto de circunstancias histricas especificas.

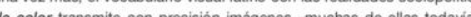
mentedes $y$ reflexiones distintas dentro del universo de ta represent visual contemporánea. deentrodearte]

Comisariado y programación en el Departamento de Obras de Arte Audiovisu

Administracion: Milagros Martinez Pérez

Administracion. Milagros Mant

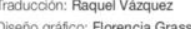
Agradecimientos: centrodrearte.com; Embajada de Suiza en España: Embają
Brasil en España, Pro Helvetia, Swissair; AECI. Agencia Española de Coope Internacional: Amparo Lozano, Carlos Giménez, Guillermo Santamarina, Ten Foto portada: Mariana Botey, The Passage of a Few. Fotogratia de las peliculas: Joaquin Cortés 

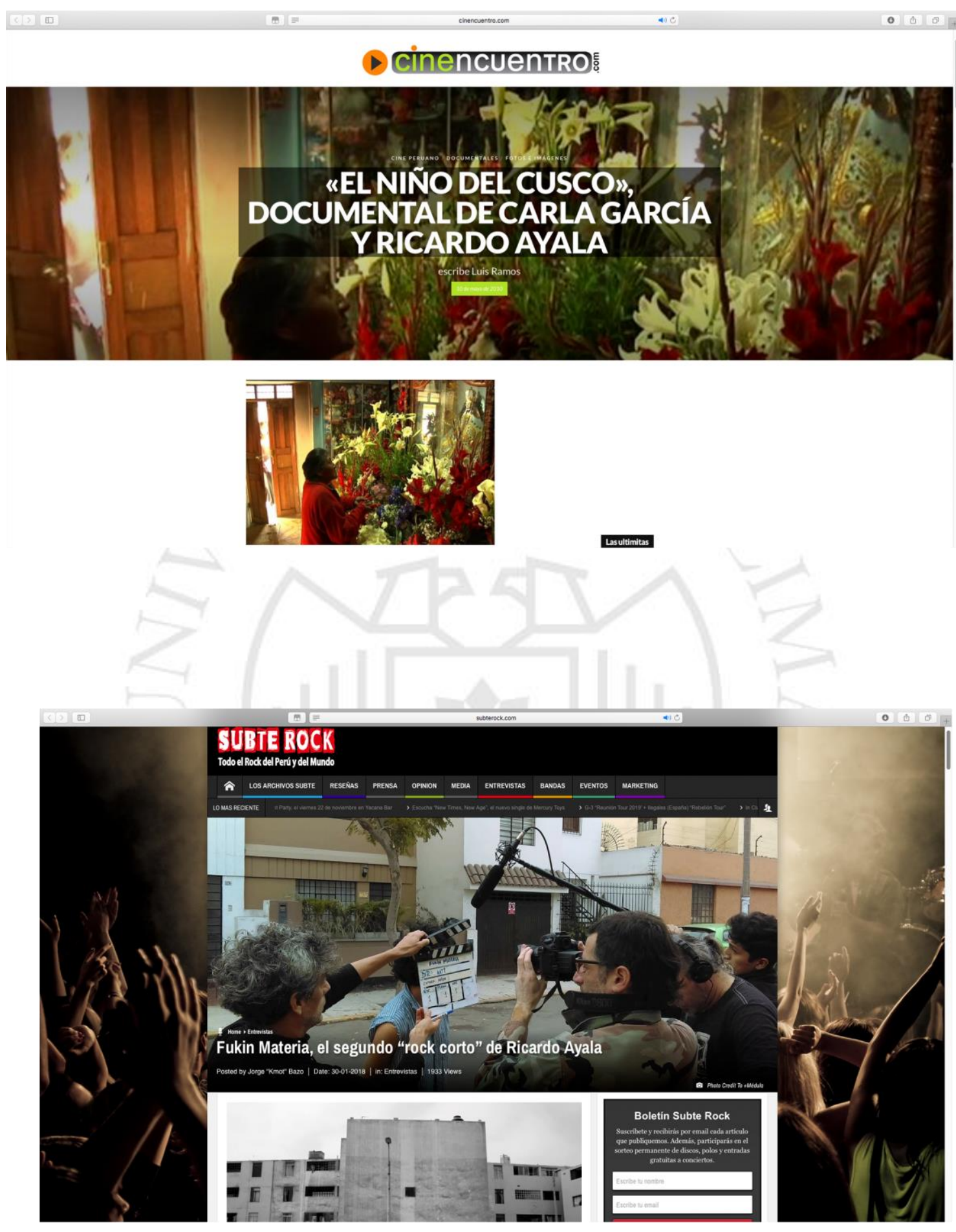


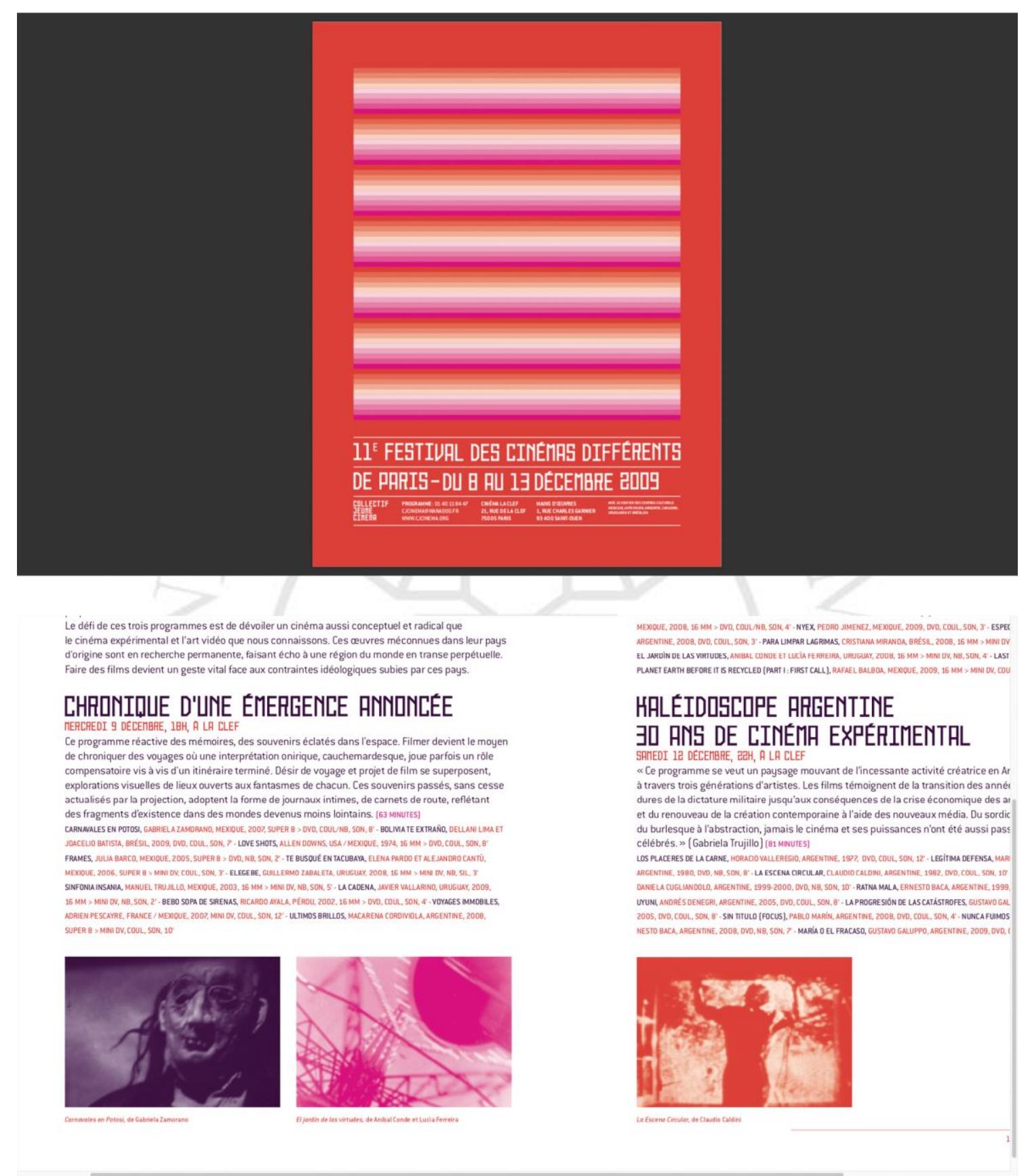




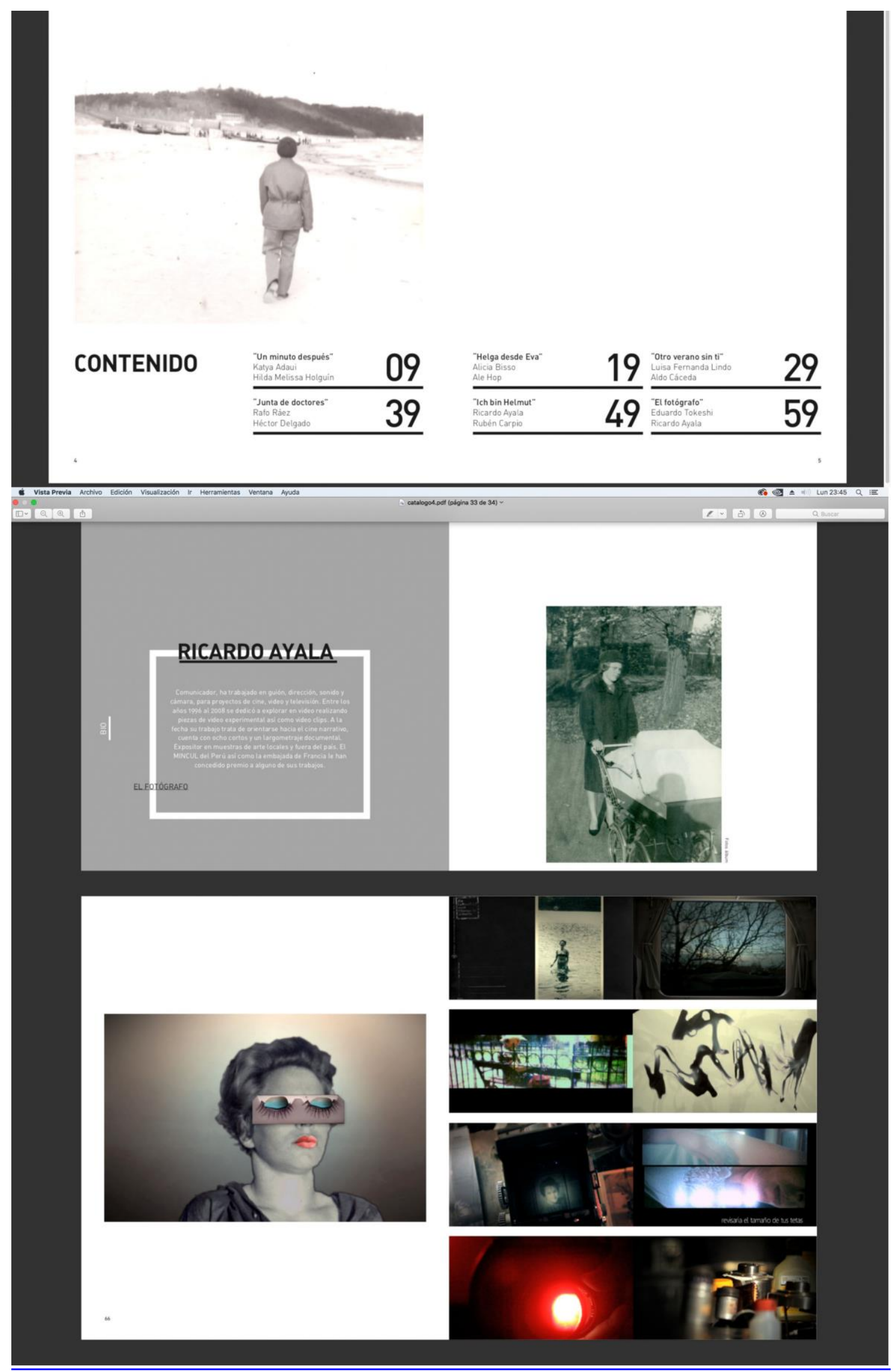

